
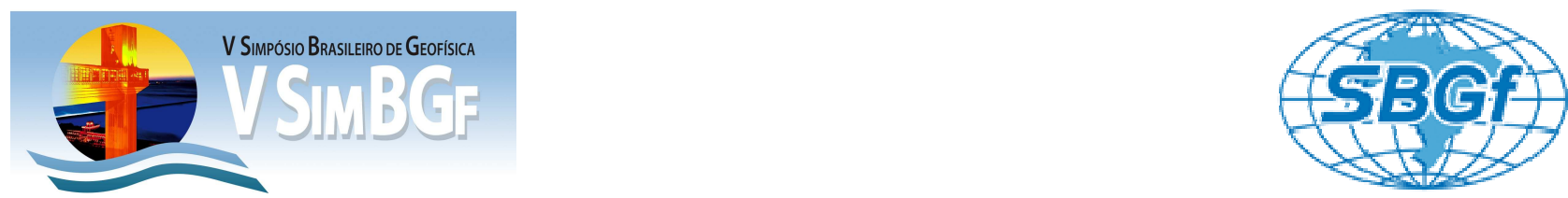

\title{
Permoporosidade computacional de rochas da Bacia do Rio do Peixe
}

Lizianne Carvalho Medeiros ${ }^{1}$, José Agnelo Soares ${ }^{1}$, Adriana Lemos Porto ${ }^{2}$

${ }^{1}$ Universidade Federal de Campina Grande, ${ }^{2}$ Instituto Federal de Educação da Paraíba.

Copyright 2012, SBGf - Sociedade Brasileira de Geofísica

Este texto foi preparado para a apresentação no V Simpósio Brasileiro de Geofísica, Salvador, 27 a 29 de novembro de 2012. Seu conteúdo foi revisado pelo Comitê Técnico do V SimBGf, mas não necessariamente representa a opinião da SBGf ou de seus associados. É proibida a reprodução total ou parcial deste material para propósitos comerciais sem prévia autorização da SBGt.

\section{Resumo}

Neste trabalho a porosidade e a permeabilidade de amostras de rochas provenientes da Bacia do Rio do Peixe, localizada no extremo oeste do estado da Paraíba, são estimadas a partir de imagens microtomográficas. Aqui é realizada a comparação das propriedades estimadas computacionalmente com os valores medidos através do método convencional de injeção de nitrogênio. Foram analisados quatro plugues de rocha, sendo três deles de arenito e um de folhelho. Para a estimação computacional da porosidade foi adotado o método do threshold e os valores de permeabilidade foram estimados pela solução numérica da equação de fluxo de Navier-Stokes. As imagens microtomográficas foram obtidas em plugues de rocha e em subamostras destes plugues. A resolução das imagens obtidas foi de $24 \mu \mathrm{m}$, para os plugues, e de $8 \mu \mathrm{m}$ para as subamostras. $O$ valor de threshold que se mostrou adequado para estimar a permoporosidade das subamostras foi igual a 50. Nos plugues a resolução alcançada está abaixo da necessária. A permeabilidade foi estimada com precisão aceitável para as subamostras de granulometria mais grossa, sendo necessárias imagens de mais alta resolução para a estimação dessa propriedade em amostras de granulometria mais fina, como siltes e folhelhos. Os resultados deste trabalho mostram que a relação entre as propriedades permoporosas segue aproximadamente 0 modelo de Kozeny-Carman, independente da escala de análise, o que permite extrapolar a sua interpretação para uma escala maior, como a de estudos de campo.

\section{Introdução}

A Bacia do Rio do Peixe (BRP) consiste de uma bacia interior da região nordeste do Brasil, de idade majoritariamente cretácica, localizada no extremo oeste do estado da Paraíba. A BRP apresenta uma coluna sedimentar que é atribuída ao estágio rifte, de idade neocomiana, de acordo com estudos bioestratigráficos (Ponte et al. 1991). Lima Filho (1991) caracterizou litofaciologicamente as três formações da BRP, da base para o topo, Formação Antenor Navarro, Formação Sousa e Formação Rio Piranhas. A Formação Antenor Navarro foi descrita como composta por conglomerados e arenitos grossos arcosianos, associados a arenitos médios a finos, intercalados com siltitos e argilitos. Esta formação teria sido gerada por um sistema fluvial anastomosado e por leques aluviais. A Formação Sousa é caracterizada pela predominância de folhelhos e siltitos avermelhados e delgadas lentes de calcários, além de intercalações de arenitos finos a grossos. Este autor sugeriu que a sedimentação ocorreu em águas calmas, em ambiente lacustre raso ou de planície de inundação, com influência fluvial. A Formação Rio Piranhas é composta por arenitos grossos a conglomeráticos, com intercalações de siltitos e argilitos avermelhados.

A BRP está localizada imediatamente ao norte do Lineamento Patos, de direção E-W, na junção com ramos NE da zona de Cisalhamento Portalegre, formando duas sub-bacias principais: a sub-bacia de Sousa (SBS), que segue o trend $\mathrm{E}-\mathrm{W}$ do Lineamento Patos, e a sub-bacia Brejo das Freiras (SBBF), que exibe a direção da Falha de Portalegre (Figura 1). Adicionalmente, há uma terceira sub-bacia, de menor porte: a sub-bacia de Pombal (SBP).

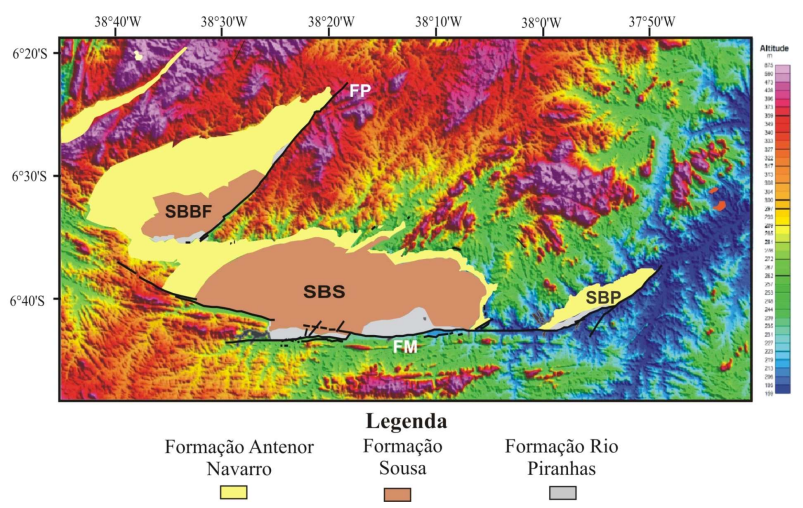

Figura 1 - Bacia do Rio do Peixe, com indicação das subbacias Sousa (SBS), Brejo das Freiras (SBBF) e Pombal (SBP), além das Falhas Malta (FM) e Portalegre (FP).

A BRP tem sido objeto de interesse face à ocorrência de óleo próximo à superfície, a NW da cidade de Sousa (PB). A qualificação e a quantificação da BRP como possível produtora de hidrocarbonetos exige 0 conhecimento das propriedades petrofísicas das suas formações geológicas. A fim de alcançar este objetivo, um projeto de P\&D está sendo conduzido por um convênio entre a Universidade Federal de Campina Grande (UFCG) e a PETROBRAS. As metas do projeto incluem a modelagem computacional das propriedades petrofísicas daquela bacia a partir de imagens microtomográficas. Neste trabalho são apresentados alguns resultados preliminares deste projeto de pesquisa.

As propriedades medidas ou estimadas neste trabalho são a porosidade e a permeabilidade de amostras de rochas (plugues) extraídas de testemunhos de dois poços estratigráficos perfurados naquela bacia (Duarte, 2009; Silva Filho, 2009). Estas propriedades são convencionalmente medidas através da introdução, nas 
amostras, de mercúrio, água ou gás sob condições controladas de pressurização. Recentemente diversos autores (Knackstedt et al., 2009; Dvorkin et al., 2011; Zhang et al., 2011a; Zhang et al., 2011b) tem demonstrado a possibilidade de estimar, entre outras, as propriedades permoporosas a partir da análise computacional de imagens das rochas obtidas por tomografia de raios $x$ de alta resolução.

O objetivo deste trabalho é estimar as propriedades permoporosas de rochas provenientes da BRP a partir de imagens microtomográficas, definindo o procedimento de análise, avaliando as variáveis que podem afetar o procedimento, e comparando os resultados alcançados com aqueles obtidos através de métodos convencionais de análise petrofísica.

\section{Metodologia}

Neste trabalho foram utilizados métodos de injeção gasosa nos plugues para a medição da porosidade e da permeabilidade, e o método de imageamento das mesmas amostras por microtomografia de raios $\mathrm{x}$.

Quatro plugues oriundos da BRP foram ensaiados para a medição física das suas porosidades, sendo três deles de arenito (plugues A4, A7 e A9) e um de folhelho (plugue F9). Os plugues são amostras cilíndricas com 1,5 polegada de diâmetro e de 4 a $5 \mathrm{~cm}$ de comprimento. Para o ensaio físico de porosidade foi utilizado o equipamento Ultra-Pore $400^{\circledR}$ fabricado pela CoreLab Instruments.

O método de medição de porosidade é baseado na lei de Boyle-Mariotte, uma das leis fundamentais dos gases, que relaciona a variação de volume e pressão de um gás ideal em temperatura constante. Neste trabalho o gás utilizado foi o nitrogênio.

O porosímetro apresenta uma câmara de gás de volume constante $V_{1}$, onde $o$ gás é injetado e armazenado a uma pressão $P_{1}$. Esta câmara de gás está ligada à câmara de compressão da amostra de volume V. Quando a câmara de compressão contém uma amostra cujo volume de sólidos é $V_{A}$, ela não pode conter mais do que $V-V_{A}$ de volume de gás. Então, no momento em que a válvula de ligação da câmara de gás com a câmara de compressão é aberta, e o gás é liberado isotermicamente para penetrar na amostra, ocorre uma variação de volume $\Delta \mathrm{V}$ e uma nova pressão $P_{2}$ é medida, onde $\Delta V$ é o volume de gás na amostra, ou em outras palavras, o volume de poros da amostra. A porosidade é então calculada como a razão entre o volume de poros e o volume total da amostra, o qual é medido facilmente devido à forma cilíndrica da amostra.

A permeabilidade é medida através da aplicação da Lei de Darcy, que diz que a perda de pressão que um fluido sofre ao atravessar um meio poroso é diretamente proporcional à vazão desse fluido. A permeabilidade absoluta do meio é uma constante de proporcionalidade entre a vazão e a perda de pressão. Desta forma, conhecendo-se as dimensões da amostra, basta monitorar a vazão e a perda de pressão do fluido para se obter a permeabilidade absoluta do meio a um fluido com dada viscosidade. O equipamento utilizado para a medição física da permeabilidade foi o Ultra-Perm $600^{\circledR}$ fornecido pela CoreLab Instruments.

$O$ imageamento dos plugues e das subamostras foi realizado através do equipamento Skyscan $1173^{\circledR}$ fabricado pela Bruker MicroCT (Figura 2). Este equipamento consiste basicamente de uma fonte de raios $x$ de alta energia e de um detector plano livre de distorção. Ele gera tomogramas, no plano horizontal do objeto, com resolução que varia com as dimensões deste. São gerados milhares de tomogramas por objeto.

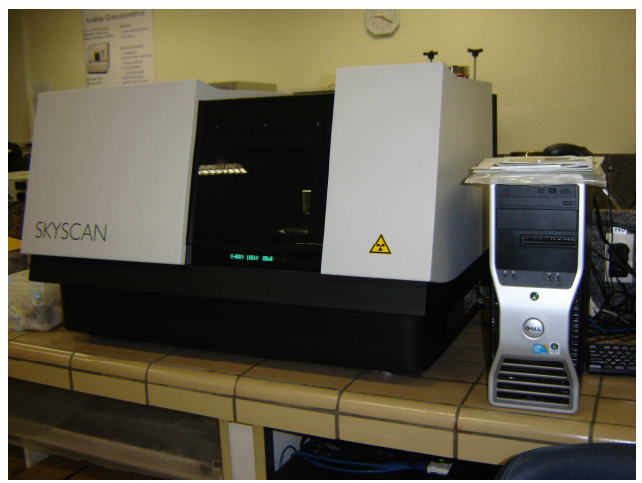

Figura 2 - Microtomógrafo Skyscan $1173^{\circledR}$.

A fim de investigar o efeito do tamanho do objeto sobre a resolução das imagens tomográficas foram realizados ensaios com os plugues, e, posteriormente, foram extraídas subamostras destes plugues em forma de pequenos paralelepípedos com dimensões aproximadas de $10 \mathrm{~mm} \times 10 \mathrm{~mm} \times 7 \mathrm{~mm}$. As resoluções alcançadas foram de $24 \mu \mathrm{m}$ e $8 \mu \mathrm{m}$, para os plugues e as suas subamostras, respectivamente. O espaço poroso é melhor observado nas imagens de maior resolução, como pode ser observado na Figura 3.

Os dados são registrados na forma de projeções do objeto, em diversos ângulos, sobre o detector plano, obtendo as chamadas radiografias. Em seguida esses dados brutos são processados a fim de gerar os tomogramas bidimensionais (slices), os quais quando empilhados, geram uma imagem tridimensional do objeto imageado. Para este fim foi utilizado o software de processamento NRECON, fornecido pela Bruker MicroCT.
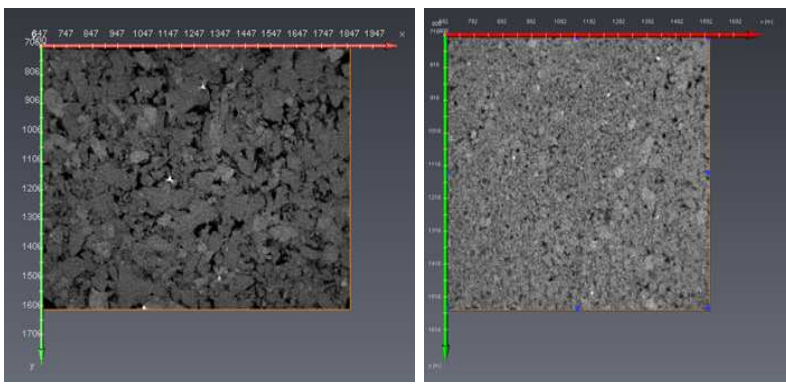

Figura 3 - Imagem da amostra A7 com $8 \mu \mathrm{m}$ e $24 \mu \mathrm{m}$, respectivamente. 
Para a análise das imagens de microtomografia está sendo utilizado um software especializado (AvizoFire ${ }^{\circledR}$ ) de visualização e quantificação do espaço poroso (Figura 4).

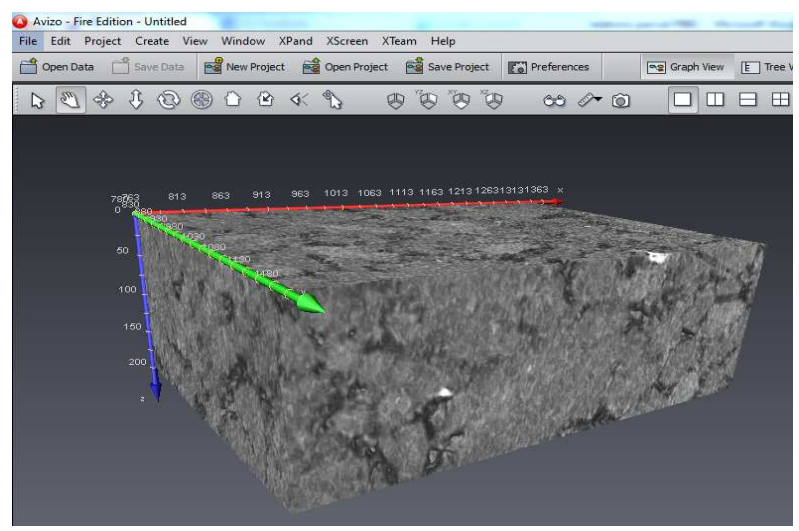

Figura 4 - Visualização 3D de um conjunto de slices da sub-amostra A7.

Para a estimação dos valores de porosidade é necessário abrir o arquivo da imagem de microtomografia de raio $x$, e anexar a ela o orthoslice e o boundingbox, para visualização. Devido a limitações computacionais para o processamento das imagens que compõem toda a sub-amostra, aplica-se o ExtractSubvolume para delimitar a área da amostra a ser trabalhada. Assim a amostra é dividida em vários grupos com mesmo número de slices. As imagens são então submetidas ao processo de segmentação. Para isto foi utilizado, neste trabalho, o método threshold. Ele se baseia na determinação de um limiar de tom de cinza (ou cor) que separa a matriz mineral dos poros. A matriz é reconhecida como sendo os pixels que apresentam cor cinza mais clara, e os poros como sendo os pixels mais escuros da imagem. Isto pode ser visto na Figura 5.

O programa dispõe de uma ferramenta para medição do volume de material existente na imagem, a materialStatistics. Através dessa ferramenta é possível obter o volume do espaço poroso (espaços que apresentam pixels escuros), e também é calculado o volume da matriz mineral (espaços que contém pixels mais claros).
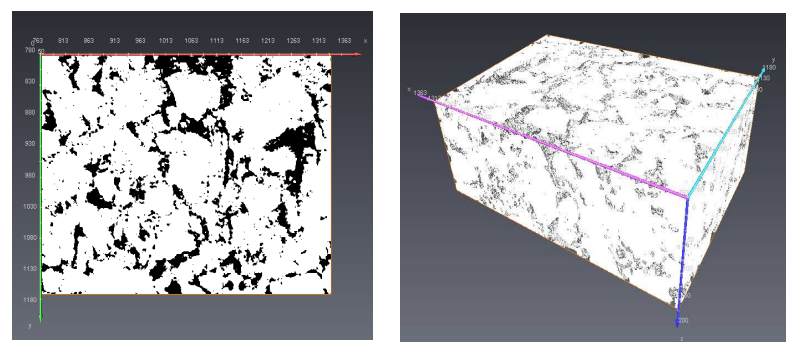

Figura 5 - Imagens 2D e 3D obtidas após a aplicação do threshold.

A Figura 6 ilustra a tabela obtida através desta ferramenta, onde o material exterior corresponde ao espaço poroso e o material interior à matriz mineral.
Como observado nesta figura, outras grandezas são obtidas por essa ferramenta, mas para o cálculo da porosidade é necessário apenas o volume exterior e interior. O cálculo da porosidade da subamostra é por sua vez a média aritmética dos valores de porosidade obtida para cada grupo de slices. O esquema de trabalho utilizado para a quantificação da porosidade é apresentado na Figura 7.

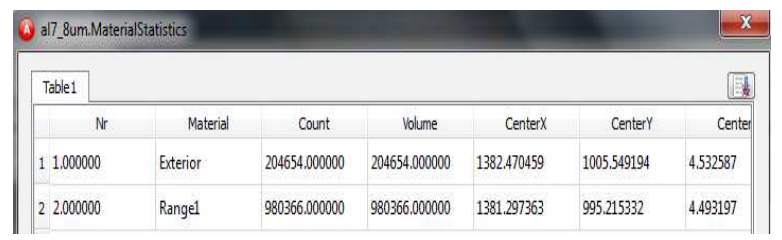

Figura 6 - Tabela de valores da ferramenta MaterialStatistics.

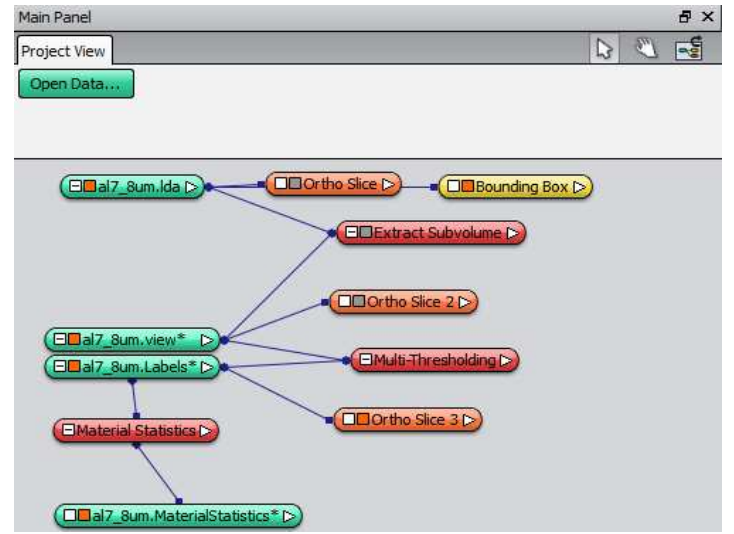

Figura 7 - Esquema de trabalho para a quantificação da porosidade.

A permeabilidade absoluta do meio poroso, a partir do conjunto de imagens microtomográficas, é estimada através de simulação numérica.

Para o cálculo da permeabilidade absoluta, o início do processo é o mesmo realizado no estudo da porosidade. É necessário abrir 0 arquivo das imagens de microtomografia, anexar as ferramentas de visualização (orthoslice e boundingbox), delimitar a área a ser estudada através do ExtractSubvolume, e segmentar o conjunto de imagens. O próximo passo é escolher a ferramenta XLab Hydro, e configurar quais serão as condições de contorno, os valores de entrada dessas condições, a direção do fluxo e a viscosidade do fluido que serão adotados na simulação (Figura 8). A ferramenta fornece dados de saída como o campo de pressão e a velocidade para a região em estudo.

$\mathrm{Na}$ simulação da permeabilidade foram considerados os seguintes parâmetros:

- Viscosidade do fluido: 0,001 Pa.s;

- Pressão de entrada: $130 \mathrm{KPa}$;

- Pressão de saída: $100 \mathrm{KPa}$. 


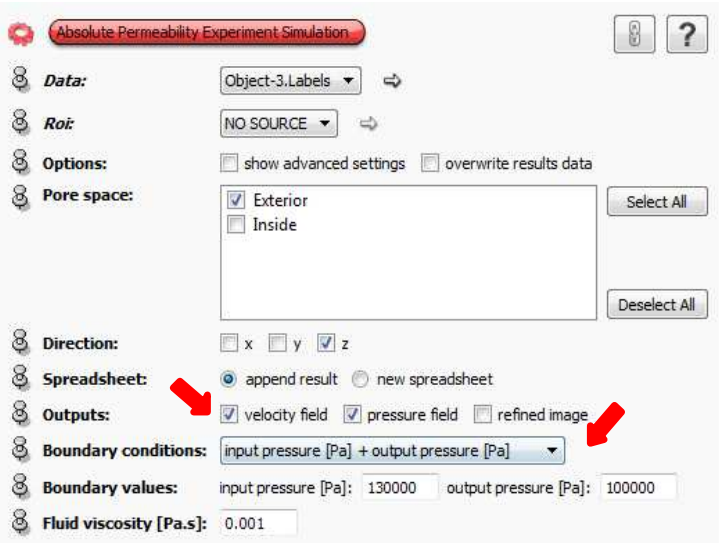

Figura 8 - Opções de configuração do XLab Hydro para a simulação numérica da permeabilidade.

Para a simulação da permeabilidade cada subamostra foi dividida em ROls (regions of interest). Em seguida a permeabilidade de cada ROI foi simulada, sendo a permeabilidade da subamostra estimada como a média das permeabilidades dos ROls que pertencem àquela subamostra.

Embora Tiab \& Donaldson (2004) recomendem o uso da média geométrica para o cálculo da permeabilidade a partir de um conjunto de valores simulados, neste trabalho observou-se que a média aritmética dos ROls se aproxima melhor dos valores de permeabilidade medidos fisicamente. Portanto, esta foi a média adotada.

Ao término do processamento é obtida uma tabela com os valores de permeabilidade absoluta (em Darcy e na unidade escolhida para a análise, neste caso, $\mu \mathrm{m}^{2}$ ) e a vazão do fluxo na amostra, como apresentado na Figura 9.

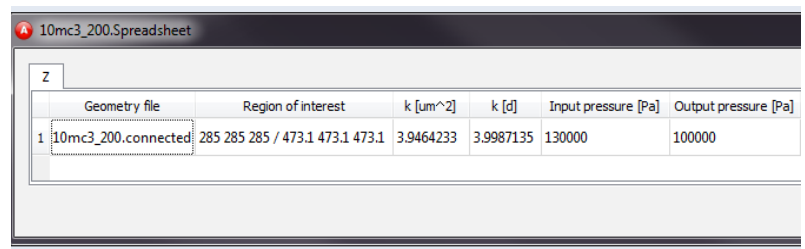

Figura 9 - Tabela com resultados da ferramenta $X L a b$ Hydro para a estimativa da permeabilidade.

\section{Resultados}

A fim de avaliar o nível ideal de threshold para a realização da segmentação das imagens, e consequente determinação da porosidade e da permeabilidade das amostras, foram testados diversos valores de threshold e feita a comparação dos valores de porosidade estimados com aqueles obtidos nos ensaios físicos. A Figura 10 apresenta os valores de porosidade estimados, para cada plugue e subamostra, em função dos valores de threshold, bem como os valores de porosidade medidos em laboratório.

Duas observações podem ser feitas com relação à Figura 10: a) Os valores de porosidade crescem com o aumento do valor de threshold. Isto acontece porque aumentar o threshold equivale a admitir que pixels de cor cinza mais claros pertencem ao espaço poroso. Comparando os valores de porosidade obtidos nos ensaios físicos com aqueles indicados nas curvas cheias da Figura 10, adotou-se o valor de threshold como igual a 50. Este valor de threshold corresponde a aproximadamente o valor ideal médio para as amostras argilosas. Posteriormente, Zhang et al. (2011b) confirmou este valor de threshold como sendo adequado. b) Os valores de porosidade calculados, para um dado threshold, são maiores para as subamostras do que para os plugues correspondentes. Isto ocorre devido à resolução insuficiente das imagens microtomográficas obtidas nos plugues. Uma exceção ocorre para o plugue (e correspondente subamostra) de folhelho F9, para os quais se conclui que as resoluções obtidas tanto nas imagens do plugue quanto de sua correspondente subamostra são ambas inadequadas.

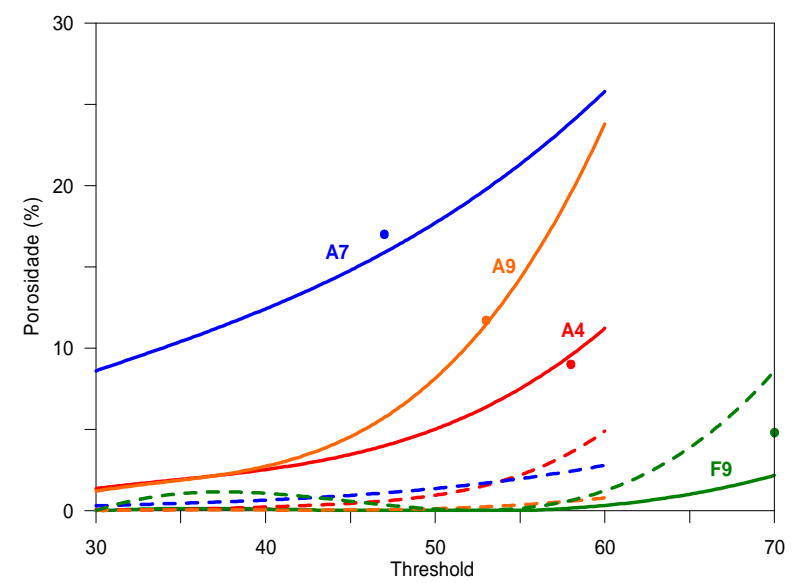

Figura 10 - Valores de porosidade em função dos valores de threshold para os plugues (curvas tracejadas) e suas correspondentes subamostras (curvas cheias). Os valores de porosidade medidos em laboratório são apresentados como pontos cheios.

A Figura 11 apresenta uma comparação entre os valores de porosidade medidos através dos ensaios físicos e os correspondentes valores de porosidade estimados através da simulação computacional. Vê-se nesta figura que os valores de porosidade estimados a partir das imagens microtomográficas nas subamostras são aproximadamente iguais aos valores de porosidade medidos nos ensaios físicos, pois se a correspondência fosse perfeita, os pontos da Figura 11 cairiam sobre a linha diagonal positiva do gráfico. Isto indica que a resolução $(8 \mu \mathrm{m})$ alcançada nas subamostras é suficiente para obter estimativas corretas de porosidade através da simulação computacional, especialmente para as amostras de granulometria mais grosseira, como é caso da amostra A7. Por outro lado, a Figura 11 mostra claramente que a resolução obtida nas imagens microtomográficas dos plugues $(24 \mu \mathrm{m})$ é insuficiente para a estimativa da porosidade, o que resulta em valores simulados de porosidade muito inferiores aqueles de fato medidos nos ensaios físicos. Isto ocorre porque sob resolução insuficiente apenas os poros maiores são reconhecidos. 


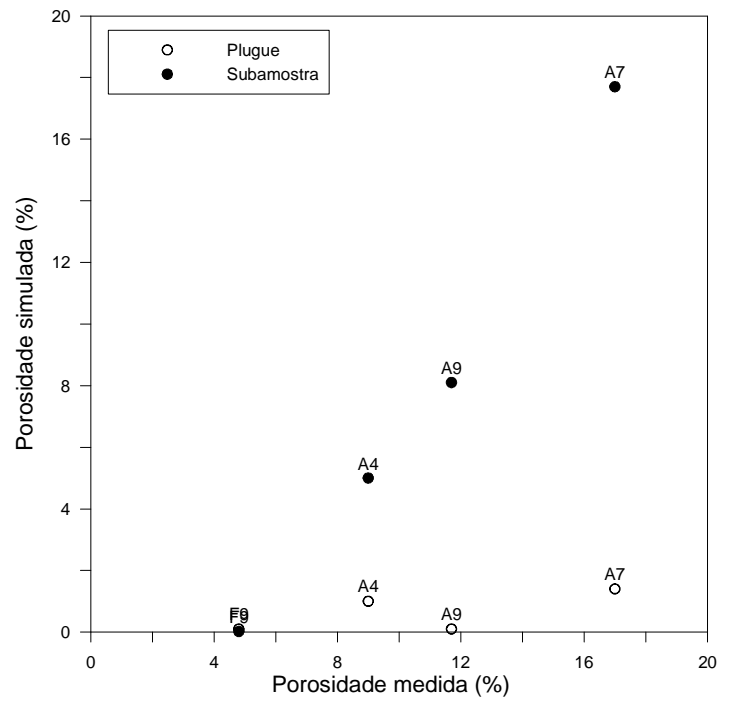

Figura 11 - Comparação entre os valores de porosidade estimados na simulação e os obtidos nos ensaios físicos.

A Figura 12 apresenta os resultados obtidos na simulação da permeabilidade das quatro subamostras em comparação com os respectivos valores de permeabilidade medidos fisicamente através do fluxo de gás. Desta figura pode-se ver que os valores de permeabilidade estimados se encontram na mesma ordem de grandeza para as amostras de granulometria mais grosseira (A7 e A4), mas apresentam uma ligeira discrepância para as amostras de granulometria mais fina (A9 e F9). Deve-se ressaltar que, devido a limitações computacionais, os valores de permeabilidade foram simulados para sub-regiões das subamostras, enquanto que os ensaios físicos foram realizados nos respectivos plugues.

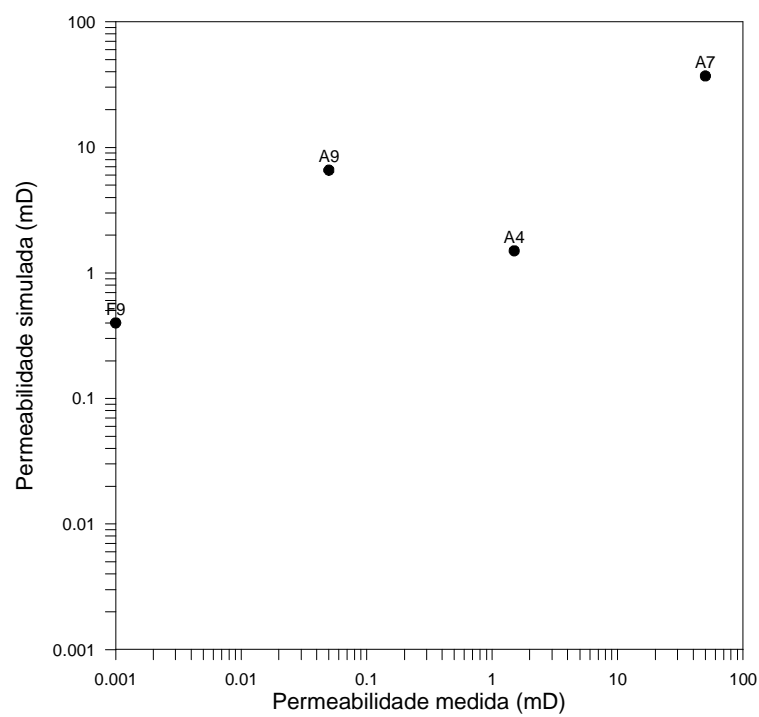

Figura 12 - Comparação entre a permeabilidade estimada na simulação e a obtida nos ensaios físicos.

A Figura 13 apresenta duas fatias tomográficas (slices) das subamostras $A 7$ e $A 9$, respectivamente, de onde se pode observar a granulometria dessas subamostras. Claramente a subamostra A7 apresenta grãos maiores que a subamostra $A 9$, o que resultou em uma simulação de permeabilidade mais aproximada do valor medido para a subamostra $A 7$, como pode ser visualizado como uma menor distância do ponto desta amostra em relação à diagonal na Figura 12.
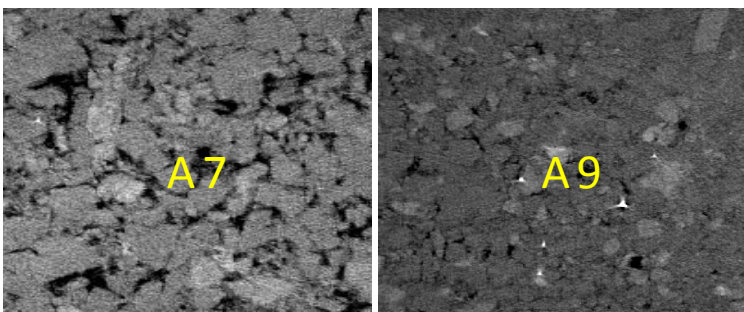

Figura 13 - Fatias tomográficas das subamostras A7 e $A 9$, as quais mostram que possuem granulometria mais grosseira e mais fina, respectivamente.

A Figura 14 apresenta os valores de permeabilidade medidos e estimados contra os respectivos valores de porosidade. Cada subamostra, seus respectivos ROls e plugues são identificados pelo símbolo que os representam. Observa-se, de modo geral, que estas propriedades, independentemente da escala, se relacionam aproximadamente na forma da equação de Kozeny-Carman, a qual prevê um aumento exponencial da permeabilidade com o aumento linear da porosidade. $\mathrm{Na}$ relação de Kozeny-Carman apresentada nesta figura foi adotada a constante igual a 5, conforme discutido por Wyllie \& Gregory (1955). Os ROls de uma mesma subamostra apresentam valores de permeabilidade e porosidade que se diferenciam da subamostra a qual pertencem, o que é resultante da variação espacial na distribuição dos tamanhos de poros e grãos minerais.

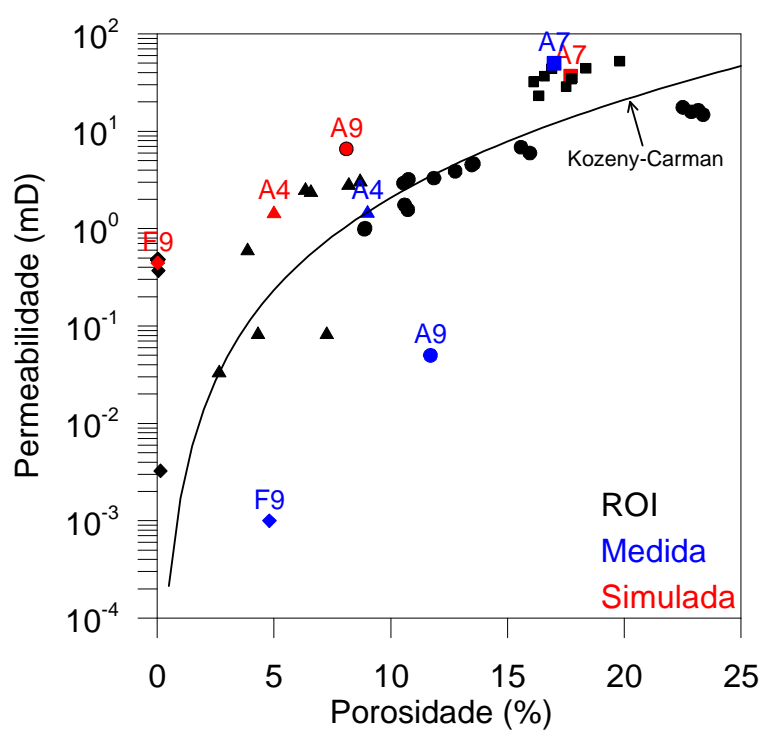

Figura 14 - Valores de porosidade e permeabilidade medidos e estimados em amostras, subamostras e ROls. A relação de Kozeny-Carman é mostrada como referência. 


\section{Conclusões}

Este trabalho demonstra a viabilidade da determinação das propriedades permoporosas de rochas a partir de imagens de microtomografia de raios $x$, sendo a técnica aplicada a amostras de rochas da Bacia do Rio do Peixe.

A resolução das imagens necessária para a correta simulação dessas propriedades depende do tamanho dos grãos e dos poros das rochas analisadas. Para arenitos, uma resolução de $8 \mu \mathrm{m}$ se mostrou suficiente, enquanto que imagens com resolução de $24 \mu \mathrm{m}$ se mostraram inadequadas para tal. Com o equipamento utilizado neste trabalho, para se obter imagens de maior resolução é preciso diminuir as dimensões da amostra irradiada, de modo que a resolução de $8 \mu \mathrm{m}$ foi obtida em subamostras com dimensões em torno de $10 \mathrm{~mm} \times 10 \mathrm{~mm} \times 7 \mathrm{~mm}$, enquanto que a resolução de $24 \mu \mathrm{m}$ foram obtidas em amostras cilíndricas com 1,5 polegada de diâmetro e cerca de $5 \mathrm{~cm}$ de comprimento.

A segmentação das imagens, ou seja, a separação entre o espaço poroso e os grãos minerais se deu em função da adoção de threshold que define o limiar de tons de cinza entre uma região e a outra. Nas imagens processadas neste trabalho o tom de cinza igual a 50 foi adotado como threshold.

As propriedades permoporosas simuladas neste trabalho foram comparadas com medições laboratoriais. Os valores de porosidade estimados por microtomografia, nas subamostras cujas imagens possuem maior resolução, foram todos quase coincidentes com os valores medidos nos ensaios laboratoriais. Já as porosidades estimadas com base nas imagens microtomográficas dos plugues foram muito inferiores às porosidades de fato medidas. Isto demonstra a insuficiência de resolução das imagens obtidas nos plugues.

Para a simulação da permeabilidade em sub-regiões das subamostras (ROIs) observou-se que os valores aproximadamente coincidem com a permeabilidade medida em ensaios físicos, especialmente para as amostras de granulometria não muito fina. Isto indica a necessidade de aumentar a resolução das imagens para a correta simulação de propriedades permoporosas de rochas de granulometria muito fina como siltes e folhelhos.

Os valores estimados de porosidade e permeabilidade indicam que estas propriedades se relacionam na forma aproximada do modelo de Kozeny-Carman. Isto vale para as subamostras, para sub-regiões dessas subamostras, e para as medições físicas realizadas nos plugues. Isto indica que o conhecimento da relação entre estas propriedades, mesmo quando determinado na pequena escala (análise laboratorial), pode ser extrapolado para escalas maiores, como nos estudos de campo.

\section{Agradecimentos}

Os autores agradecem ao convênio PETROBRAS/UFCG TC 0050.0057323.10.9 pelo financiamento da pesquisa e à PETROBRAS pela permissão para a publicação destes resultados. A primeira autora é bolsista PIBIC/CNPq

\section{Referências}

Duarte, I.S. 2009. Rochas Reservatório da Bacia de Sousa - PB. Relatório PIBIC. Departamento de Geologia da UFRJ.

Dvorkin,J; Derzhi, N; Diaz, E; Fang, Q. 2011. Relevance of computational rock physics. Geophysics, Vol. 76, n. 5.

Knackstedt, M.A.; Latham, S.; Madadi, M.; Sheppard, A.; Varslot, T.; Arns, C. 2009. Digital rock physics: 3D imaging of core material and correlations to acoustic and flow properties. The Leading Edge, January 2009.

Lima Filho, M.L. 1991. Evolução tectono-sedimentar da Bacia do Rio do Peixe-PB. Dissertação de Mestrado. UFPE. Recife.

Ponte, F.C., Hashimoto, A.T., Dino, R., coords. (1991). Geologia das bacias sedimentares mesozóicas do interior do Nordeste do Brasil. PETROBRAS/CENPES/DIVEX/ SEBIPE, relat. interno.

Silva Filho, R.P. 2009. Análise de fácies da Formação Sousa (Cretáceo Inferior), bacia de Sousa (PB), e seu contexto em um sistema petrolífero. Trabalho de Conclusão de Curso. Departamento de Geologia da UFRJ.

Tiab, D.; Donaldson, E.C. 2004. Petrophysics. Theory and practice of measuring reservoir rock and fluid transport properties. Elsevier.

Wyllie, M.R.J., Gregory, A.R. 1955. Fluid flow through unconsolidated porous aggregates: effect of porosity and particle shape on Kozeny-Carman constants. Industrial and Engineering Chemistry, Vol. 47, № 7, pp. 1379-1388.

Zhang, S; Saxena, S; Barthelemy, P; Marsh, M; Mavko, G; Mukerji, T. 2011a. Poromechanics Investigation at Pore-scale Using Digital Rock Physics Laboratory. Comsol Conference, 2011.

Zhang, S; Klimentidis, R.E; Barthelemy, P. 2011b. Porosity and permeability analysis On nanoscale fib-sem 3d imaging of shale rock. SCA Symposium, 2011. 